\title{
Electrically evoked saccades from the dorsomedial frontal cortex and frontal eye fields: a parametric evaluation reveals differences between areas
}

\begin{abstract}
Using electrical stimulation to evoke saccades from the dorsomedial frontal cortex (DMFC) and frontal eye fields (FEF) of rhesus monkeys, parametric tests were conducted to compare the excitability properties of these regions. Pulse frequency and pulse current, pulse frequency and train duration, and pulse current and pulse duration were varied to determine threshold functions for a $50 \%$ probability of evoking a saccade. Also a wide range of frequencies were tested to evoke saccades, while holding all other parameters constant. For frequencies beyond $150 \mathrm{~Hz}$, the probability of evoking saccades decreased for the DMFC, whereas for the FEF this probability remained at $100 \%$. To evoke saccades readily from the DMFC, train durations of greater than $200 \mathrm{~ms}$ were needed; for the FEF, durations of less than 100 ms were sufficient. Even though the chronaxies of neurons residing in the DMFC and FEF were similar (ranging from 0.1 to $0.24 \mathrm{~ms}$ ) significantly higher currents were required to evoke saccades from the DMFC than FEF. Thus the stimulation parameters that are optimal for evoking saccades from the DMFC differ from those that are optimal for evoking saccades from the FEF. Although the excitability of neurons in the DMFC and FEF are similar (due to similar chronaxies), we suggest that the density of saccaderelevant neurons is higher in the FEF than in the DMFC.
\end{abstract}

Key words Dorsomedial frontal cortex - Frontal eye fields - Electrical stimulation - Parameters of stimulation . Chronaxies $\cdot$ Saccades $\cdot$ Rhesus monkeys

\section{Introduction}

The dorsomedial frontal cortex (DMFC) and frontal eye fields (FEF) are involved in oculomotor control. Much evidence suggests that the coding systems utilized by

E.J. Tehovnik ( M.A. Sommer

Department of Brain and Cognitive Sciences,

Massachusetts Institute of Technology, E25-634, Cambridge,

MA 02139, USA

Fax: +1-617-253-8943, e-mail: tehovnik@ai.mit.edu the DMFC and FEF for saccade execution differ. A head-centered code seems to be operative in the DMFC, whereas an eye-centered code seems to be operative in the FEF. Saccades evoked electrically from the DMFC terminate at an orbital position that we call a termination zone (Bon and Lucchetti 1992; Lee and Tehovnik 1995; Mann et al. 1988; Schall 1991b; Schlag and Schlag-Rey 1987; Tehovnik and Lee 1993; Tehovnik et al. 1994). For different positions of the head with respect to the body, the location of a termination zone remains fixed to the head (Tehovnik and Lee 1993). Termination zones are represented topographically within the DMFC such that anterior DMFC codes for termination zones in contralateral craniotopic space, posterior DMFC codes for termination zones in central or ipsilateral craniotopic space, medial DMFC codes for termination zones in lower craniotopic space, and lateral DMFC codes for termination zones in upper craniotopic space (Lee and Tehovnik 1995; tehovnik and Lee 1993; Tehovnik et al. 1994). Once a saccade is completed, continued electrical stimulation of the DMFC rarely evokes additional saccades (Schlag and Schlag-Rey 1987); rather, continued stimulation nearly always holds the eyes within the termination zone until stimulation ceases (Tehovnik and Lee 1993; Tehovnik et al. 1994). In contrast, saccades evoked from the FEF exhibit similar directions and amplitudes irrespective of the starting eye position (Bruce et al. 1985; Goldberg and Bruce 1990; Marrocco 1978; Robinson and Fuchs 1969; Schall 1991b; Tehovnik and Lee 1993), and continued electrical stimulation produces staircase saccades without fixing the eyes in orbit (Robinson and Fuchs 1969; Schall 1991b; Schiller 1977; Tehovnik and Lee 1993).

The view that the DMFC and FEF utilize different coding systems has been challenged by the stimulation study of Russo and Bruce (1993). Using a limited set of stimultion parameters in the DMFC, they found that stimulation of this area evoked saccades that were similar to those evoked in the FEF (i.e., the amplitude and direction of saccades varied little with starting eye position). Tehovnik and Lee (1993), however, demonstrated 
that the use of suboptimal stimulation parameters in the DMFC can truncate saccades evoked from this area, making them look like saccades evoked from the FEF, or can fail to evoke saccades altogether. The purpose of the present study, therefore, was to fully characterize the DMFC and FEF in terms of the ability to evoke saccades under various parameters of stimulation. This allows an objective evaluation of the excitability of the two areas to see if they differ fundamentally or not. Furthermore, the optimal parameters for evoking saccades from the DMFC and FEF can be established for future stimulation and recording studies. Finally, by comparing the parameters required to evoke saccades from the two areas, new insight might be gained as to the distribution and conductive properties of saccade-related neurons in the areas.

\section{Materials and methods}

\section{Subjects}

Two adult rhesus monkeys (Macaca mulatta), I and L, were used. Throughout this study food was freely available. The monkeys were water-deprived overnight before each day of experimental testing. After testing, they were allowed to drink to satiation before being returned to the vivarium. The monkeys were provided for in accordance with the National Institutes of Health Guide for the Care and Use of Laboratory Animals and the guidelines of the Massachusetts Institute of Technology Committee on Animal Care.

\section{Surgery}

Monkeys were anesthetized with pentobarbital $(30 \mathrm{mg} / \mathrm{kg})$ intravenously and prepared for sterile surgery. A scleral search coil was implanted subconjunctivally (Judge et al. 1980) and a stainless steel post to restrain the head was attached to the skull with head bolts and acrylic cement. For each monkey, a recording chamber was im-

\section{Monkey L}
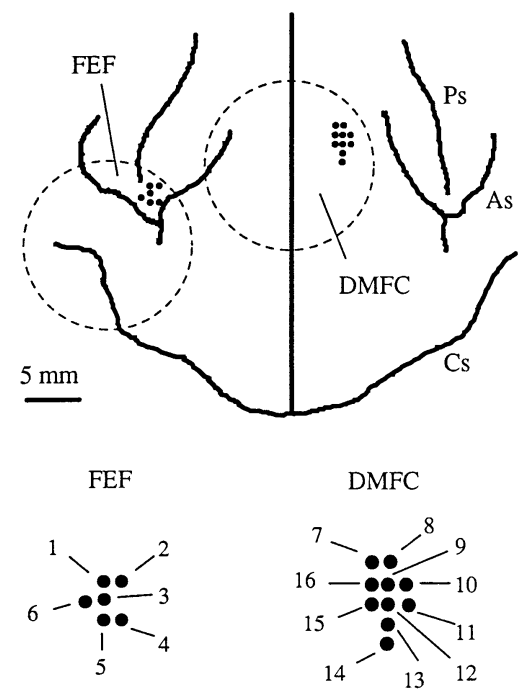

planted over the DMFC, and a second chamber was implanted over the left FEF (Fig. 1).

\section{Behavioral task}

A monkey (with head fixed) faced a $40^{\circ}$ horizontal by $30^{\circ}$ vertical LED board positioned $108 \mathrm{~cm}$ away. The animal fixated an LED $\left(0.3^{\circ}\right.$ of visual angle) for $1000 \mathrm{~ms}$ to receive a drop of apple juice. For the first $200 \mathrm{~ms}$ of fixation, the animal had to keep his eyes within a $5 \times 5^{\circ}$ window, otherwise the trial was terminated. Electrical stimulation was delivered $200 \mathrm{~ms}$ after the LED was acquired. Stimulation was delivered on $50 \%$ of the trials. Across trials, stimulation was presented in random order so that the monkey could not predict its delivery. Monkeys performed in dim light to prevent the ocular drift that occurs in total darkness (White et al. 1994).

For all parametric tests, a single fixation position located $20^{\circ}$ from the center of gaze in the hemifield ipsilateral to the side of stimulation was used. This allows saccades to be evoked from the full rostrocaudal extend of the DMFC (Tehovnik 1995; Tehovnik and Lee 1993). All the evoked saccades travelled contralateral to the side of stimulation during the tests. The position of the head with respect to the LED board was central and constant between different sessions of data collection.

Fig. 1 Top An overhead view of the dorsomedial frontal cortex $(D M F C)$ and frontal eye fields $(F E F)$ of monkeys L and I. The location of a well (dashed circle) for monkey L was found using the location of guide pins inserted into the perfused and fixed brain. The location of a well for monkey I was estimated by noting the relative distance between the genu of the arcuate (observed during surgery) and the center of a well relative to the interaural line and cerebral midline. The location of the wells for monkey I are superimposed onto the histological schematic of monkey L. Sites from which saccades were evoked are indicated by black dots. The location of a dot was determined with respect to the coordinate grid used for inserting an electrode. The principal sulcus $(P s)$, arcuate sulcus $(A s)$, and central sulcus $(C s)$ are indicated. The top represents the anterior part of the brain; the bottom represents the posterior part of the brain. Monkey L was used in the studies of Lee and Tehovnik (1995), Sommer and Tehovnik (in press), and Tehovnik and Sommer (1996); and monkey I was used in the studies of Sommer and Tehovnik (in press) and Tehovnik and Sommer (1996). Bottom Penetration sites numbered $1-31$ that correspond to the sites shown above

\section{Monkey I}
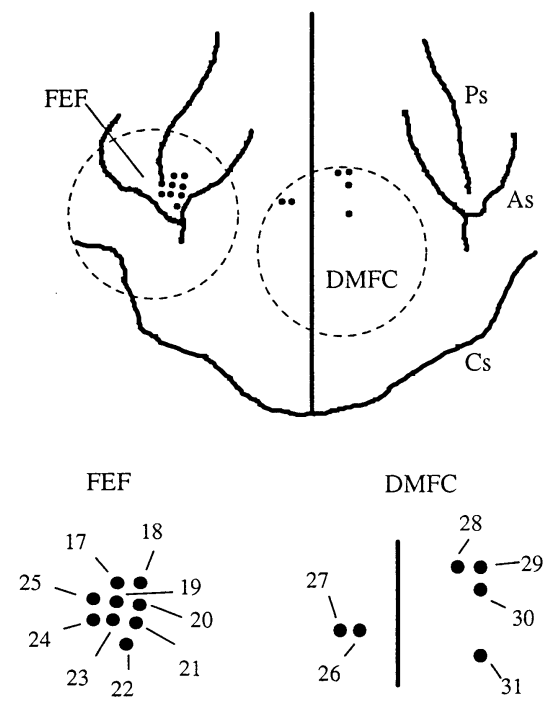
Data collection and analysis

A PDP 11/73 computer controlled the presentation of visual stimuli, the delivery of electrical stimulation, the display and collection of eye position (sampled at $333 \mathrm{~Hz}$ ), and the delivery of juice. The eyes had to achieve a velocity of at least $100 \%$ s to qualify as a saccade, and such a movement had to occur during stimulation to qualify as a stimulation-evoked saccade.

\section{Electrodes}

Glass-coated platinum-iridium electrodes with an impedance of $0.1-$ $0.2 \mathrm{M} \Omega$ at $1 \mathrm{kHz}$ were used. Their tips were conical, typically with $13 \mu \mathrm{m}$ radius at the base and length of $80 \mu \mathrm{m}$. Impedance varies inversely with the exposed surface area of an electrode tip. For platinum-iridium electrodes, the formula surface area $=0.0003 /$ impedance $^{1.4}$ conforms best to the available data (Lemon 1983, p. 74). This formula was used to estimate the exposed surface area of platinum-iridium electrodes in millimeters squared from impedance values in megohms obtained at $1 \mathrm{kHz}$. The estimated exposed surface area for electrodes was between 0.008 and $0.003 \mathrm{~mm}^{2}$.

Impedance was measured between bouts of stimulation using a $1-\mathrm{kHz}$ nanoampere tester (Bak Electronics, model A-1B) which was calibrated with a $1.0-\mathrm{M} \Omega$ resistor.

\section{Electrical stimulation}

Constant-current, charge-balanced biphasic pulses were delivered to the brain via a monopolar electrode using a Grass S88 stimulator attached to a pair of constant-current, stimulus isolation units (Grass PSIU6B). For each biphasic pulse, a cathodal and anodal pulse followed in immediate succession. Both pulses had the same amplitude and duration. Current was monitored by the voltage drop across a $1000-\Omega$ resistor that was in series with the return lead of the stimulator. The current was monitored using a Tektronix Oscilloscope (model $5103 \mathrm{~N}$, differential amplifier) and was read as the amplitude of one pulse (cathode or anode) of a biphasic pair.

Electrodes were introduced perpendicular to the dura surface with a hydraulic microdrive until action potentials were encountered. The action potentials were amplified (Bak A-1B) and filtered (Krohn-Hite 3750). During preliminary mapping of the DMFC and FEF, $400-\mu \mathrm{A}$ pulses of $0.1 \mathrm{~ms}$ delivered for $400 \mathrm{~ms}$ at $150 \mathrm{~Hz}$ were used. These values were chosen because they are effective at evoking saccades from both the DMFC and FEF (Tehovnik 1995, 1996; Tehovnik and Lee 1993).

\section{Parametric tests}

Two parameters (e.g., current compared with pulse duration) were studied together to determine the parametric values at which saccades were evoked on $50 \%$ of stimulation trials. While holding one parameter constant, the other parameter was increased or decreased until saccades were evoked on roughly five of ten trials. The $50 \%$ value was usually determined by interpolating between values obtained from an ascending or descending series of the manipulated parameter while holding all other parameters constant. Collecting such values for different combinations of the two parameters derived a parametric function. This technique has been used widely to characterize stimulated elements within the brain for many different behaviors (Gallistel et al. 1981; Tehovnik 1996; Yeomans 1990, 1995; Yeomans and Tehovnik 1988).

\section{Histology}

Monkey L was overdosed with pentobarbital, perfused with $0.9 \%$ $\mathrm{NaCl}$, and fixed with $4 \%$ paraformaldehyde. Guide pins were inserted into the cortex at specific positions around a recording chamber. The location of the electrode tracks was estimated relative to the pins. By noting the location of the genu of the arcuate (observed during surgery) and the center of the wells relative to the interaural line and cerebral midline, and by noting the electrode coordinates, the penetration sites of monkey I were estimated. Monkey I is being used for further study.

\section{Results}

\section{Stimulation sites}

The regions investigated in the DMFC and FEF are indicated for the two monkeys in Fig. 1. The best stimulation sites in the DMFC were 2-6 mm lateral to the cortical midline and 1-2 $\mathrm{mm}$ below the first units encountered on a pass. Hundreds of sites were studied in the DMFC of the two animals (monkey L: Lee and Tehovnik 1995; monkeys L and I: Sommer 1995; Tehovnik and Sommer 1996); of these a total of 16 penetration sites were studied in detail for this report. Stimulation of rostral sites (e.g., Fig. 1, site 29) evoked saccades that terminated in contra-

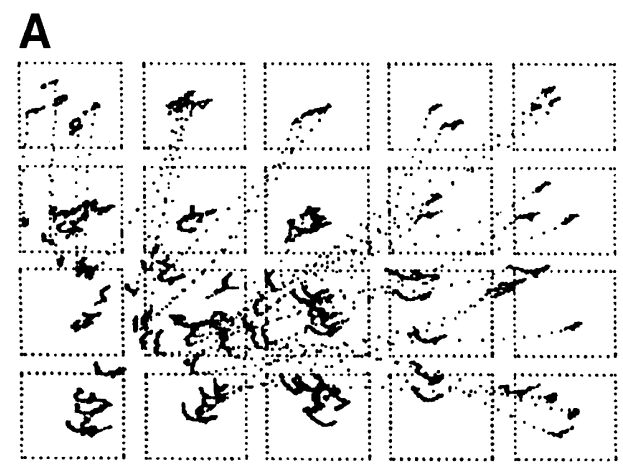

B

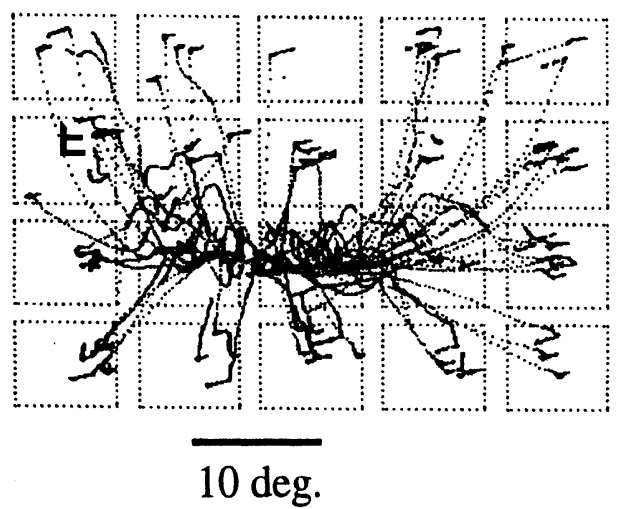

Fig. 2A, B Saccades evoked from different fixation positions are shown for an anterior (A) and posterior (B) site in the right DMFC of monkey I (see Fig. 1, penetration sites 29 and 31 respectively). Twenty different fixation positions, demarcated by dotted rectangles, were used. After fixation of a visual target located at one of the fixation positions, electrical stimulation was applied using the following parameters: current, pulse duration, frequency, and train duration of $400 \mu \mathrm{A}, 0.1 \mathrm{~ms}, 150 \mathrm{~Hz}$, and $800 \mathrm{~ms}$, respectively, were used. Electrical stimulation of the anterior right DMFC drove the eyes (eye traces represented by dotted lines) to the lower left quadrant of the LED board (A), and electrical stimulation of the posterior right DMFC drove the eyes to the center of the LED board (B). Scale bar in degrees of visual angle 


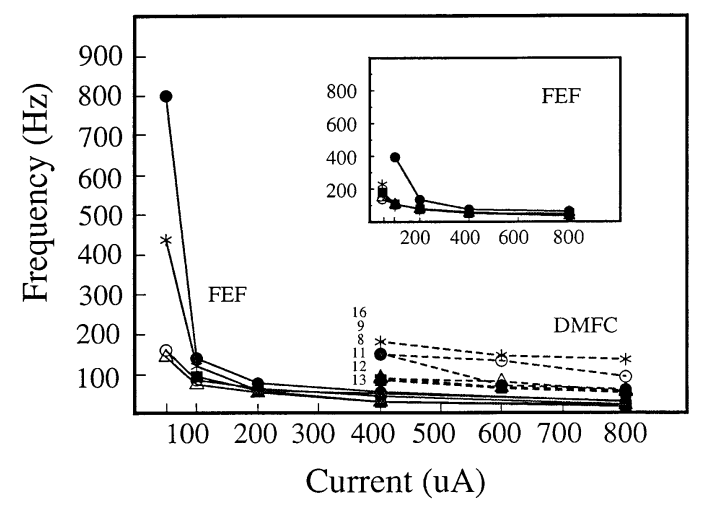

Fig. 3 Frequency threshold to evoke a saccade on $50 \%$ of stimulation trials is plotted as a function of current for the FEF and DMFC. Each curve represents data collected from one stimulation site. The pulse duration and train duration were fixed at $0.1 \mathrm{~ms}$ and $400 \mathrm{~ms}$. Using these conditions, five sites in the FEF (Fig. 1, penetration sites 17, 19, 20, 21, 23) and six sites in the DMFC (Fig. 1, penetration sites $8,9,11,12,13,16)$ were tested. Shown in the inset are data from the FEF sites (Fig. 1, penetration sites 17, 19, 20, 21, 23), where the pulse duration and train duration were fixed at $0.2 \mathrm{~ms}$ and $70 \mathrm{~ms}$. The curves for the DMFC are labeled according to site, owing to their greater variability

lateral craniotopic space (Fig. 2A), and stimulation of caudal sites (e.g., Fig. 1, site 31) evoked saccades that terminated in central craniotopic space (Fig. 2B). The sites tested within the DMFC were all within the topographic map as described previously (Tehovnik and Lee 1993).

The best stimulation sites in the FEF were in the anterior bank of the arcuate sulcus, between 2 and $6 \mathrm{~mm}$ below the first units encountered on a pass (Fig. 1). In the two monkeys, a total of 15 penetration sites were studied in detail out of hundreds previously investigated (Sommer 1995; Sommer and Tehovnik, in press, Tehovnik and Sommer 1996). Most of the FEF sites were similar to the low-threshold sites of Bruce et al. (1985), since currents of $50 \mu \mathrm{A}$ were sufficient to evoke saccades using their parameters.

\section{Frequency versus current}

The stimulation frequency needed to evoke a saccade on $50 \%$ of stimulation trials is plotted as a function of current for the FEF and DMFC (Fig. 3). In the main graph, the pulse duration and train duration were maintained at $0.1 \mathrm{~ms}$ and $400 \mathrm{~ms}$, respectively, which were standard parameters used by Tehovnik and Lee (1993). For the FEF, currents as low as $50 \mu \mathrm{A}$ were effective at evoking saccades, whereas, for the DMFC, saccades were evoked with currents greater than $200 \mu \mathrm{A}$. This finding was very consistent between sites. For the FEF, after $100 \mu \mathrm{A}$ the increased current contributed little to the decline in frequency threshold, and at $50 \mu \mathrm{A}$ the frequency threshold was quite variable, ranging from 100 to $800 \mathrm{~Hz}$. At the same levels of current (i.e., $400 \mu \mathrm{A}$ or $800 \mu \mathrm{A}$ ), the frequency threshold to evoke a saccade was always lower for the

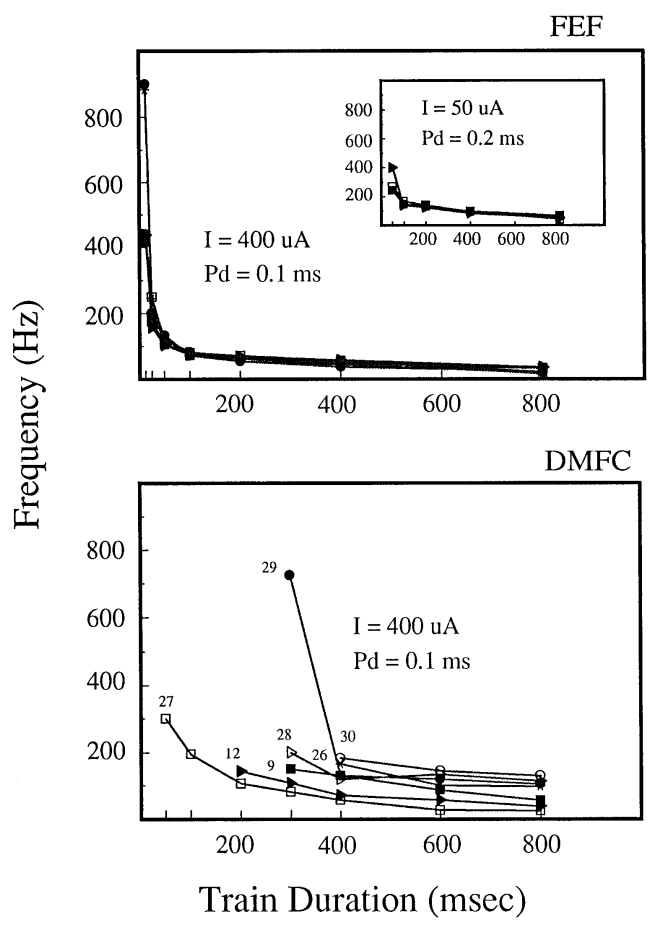

Fig. 4 Frequency threshold to evoke a saccade on $50 \%$ of stimulation trials is plotted against train duration for the FEF and DMFC. Each curve represents data collected from one stimulation site. Train durations ranging from 12 to $800 \mathrm{~ms}$ were tested. Typically, the current $(I)$ and pulse duration $(P d)$ were fixed at $400 \mu \mathrm{A}$ and $0.1 \mathrm{~ms}$. Using these conditions, seven sites in the FEF (Fig. 1, penetration sites $3,5,18,20,22,24,25)$ and seven sites in the DMFC (Fig. 1, penetration sites 9, 12, 26, 27, 28, 29, 30) were tested. Shown in the inset are data from three sites in the FEF (Fig. 1, penetration sites $3,5,22$ ), where current and pulse duration were fixed at $50 \mu \mathrm{A}$ and $0.2 \mathrm{~ms}$. The curves for the DMFC are labeled according to site, owing to their greater variability

FEF than it was for the DMFC $[t(4)=4.6, P<0.01$; $t(4)=3.7, P<0.01]$.

In the inset of Fig. 3, the frequency to evoke a saccade on $50 \%$ of stimulation trials is plotted as a function of current for the FEF using parameters of Russo and Bruce (1993). That is, these data were collected with the pulse duration and train duration at $0.2 \mathrm{~ms}$ and $70 \mathrm{~ms}$, respectively. Again currents as low as $50 \mu \mathrm{A}$ were effective at evoking saccades. For currents greater than $200 \mu \mathrm{A}$, there was little decline in frequency threshold. For currents of $100 \mu \mathrm{A}$ and higher, the frequency threshold to evoke saccades was 1.5 times higher, on average, when using parameters of Russo and Bruce than when using parameters of Tehovnik and Lee [t(19)=2.60, $P<0.01]$. Using the parameters of Russo and Bruce, saccades were not evoked from the sites tested in the DMFC.

\section{Frequency compared with train duration}

The frequency threshold to evoke a saccade on $50 \%$ of stimulation trials is plotted against train duration for sites 
in the FEF and DMFC, while using pulses of $400 \mu \mathrm{A}$ and $0.1 \mathrm{~ms}$ duration (Fig. 4). These parameters were used by Tehovnik and Lee (1993). For the FEF, the frequency threshold was always greater than $400 \mathrm{~Hz}$ for train durations of $12 \mathrm{~ms}$. With increases in train duration from 12 to $50 \mathrm{~ms}$, the threshold dropped rapidly; beyond $50 \mathrm{~ms}$ the decline in threshold was gradual.

Unlike that of the FEF, the decline in frequency threshold with increased train duration for the DMFC was more variable. For all sites except one, train durations greater than or equal to $200 \mathrm{~ms}$ were required to evoke saccades. Also, the frequency threshold to evoke saccades was higher for the DMFC than FEF. At similar levels of train duration (e.g., $400 \mathrm{~ms}$ or $800 \mathrm{~ms}$ ), the frequency threshold was significantly higher for the DMFC $[t(6)=4.1, P$ $<0.01 ; t(6)=3.7, P<0.01]$.

In the inset of Fig. 4, the frequency threshold to evoke a saccade on $50 \%$ of stimulation trials is plotted as a function of train duration for the FEF using parameters of Russo and Bruce (1993). These data were collected with the current and pulse duration of $50 \mu \mathrm{A}$ and $0.2 \mathrm{~ms}$, respectively. With these parameters, saccades were not evoked using train durations of $12 \mathrm{~ms}$ and $25 \mathrm{~ms}$. Overall, the frequency threshold to evoke saccades using the parameters of Russo and Bruce was 2.2 times higher, on average, than the frequency threshold to evoke saccades using parameters of Tehovnik and Lee $[t(9)=3.3, P<0.01]$.

\section{Frequency effects}

The probability of evoking a saccade is plotted as a function of stimulation frequency for the FEF and DMFC (Fig. 5). Current, pulse duration, and train duration were held constant at $400 \mu \mathrm{A}, 0.1 \mathrm{~ms}$, and $400 \mathrm{~ms}$, which were values used by Tehovnik and Lee (1993). For the FEF, increasing the frequency from 25 to $50 \mathrm{~Hz}$ increased the probability of evoking a saccade. For frequencies between 100 and $1000 \mathrm{~Hz}$, the probability of evoking a saccade remained at $100 \%$ for all sites tested. When parameters of Russo and Bruce (1993) were used (i.e., current, pulse duration, and train duration of $50 \mu \mathrm{A}, 0.2 \mathrm{~ms}$, and $70 \mathrm{~ms}$, respectively) the probability of evoking a saccade remained at $100 \%$ for frequencies between 200 and $1000 \mathrm{~Hz}$ (Fig. 5, FEF, inset).

For the DMFC a very different pattern emerged. The probability to evoke a saccade increased between frequencies of 50 and $100 \mathrm{~Hz}$, achieving a $100 \%$ probability at about $150 \mathrm{~Hz}$. For all sites except two (sites 10 and 29), however, the probability declined with frequencies greater than $200 \mathrm{~Hz}$. Note that such declines in probability were never observed for sites in the FEF.

\section{Current compared with pulse duration}

The current threshold to evoke a saccade on $50 \%$ of stimulation trials is illustrated as a function of pulse duration for the DMFC and FEF (Fig. 6A). Here the frequency and

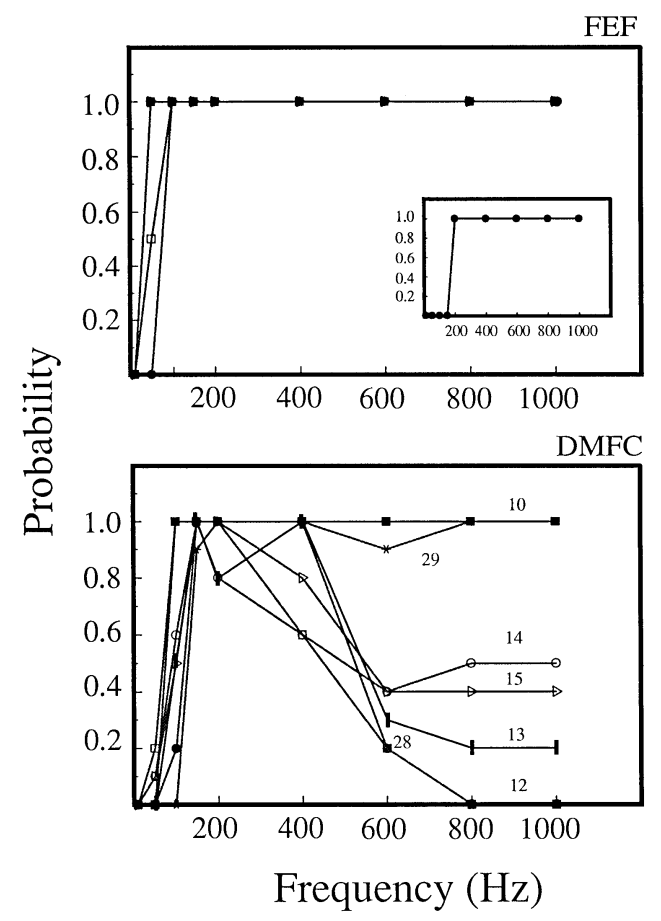

Fig. 5 The probability of evoking a saccade as a function of pulse frequency is shown for the FEF and DMFC. For frequencies ranging from 10 to $1000 \mathrm{~Hz}$, the probability was determined by dividing the number of stimulation trials during which a saccade was evoked by the total number of stimulation trials, ten in total. The current, pulse duration, and train duration were fixed at $400 \mu \mathrm{A}, 0.1 \mathrm{~ms}$, and $400 \mathrm{~ms}$, respectively. Six sites were tested in the FEF (Fig. 1, penetration sites $1,2,6,19,20,22)$ and seven sites were tested in DMFC (Fig. 1, penetration sites 10, 12, 13, 14, 15, 28, 29). Data shown in the inset, for one site (Fig. 1, penetration site 2), were obtained while current, pulse duration, and train duration were fixed at $50 \mu \mathrm{A}$ $0.2 \mathrm{~ms}$, and $70 \mathrm{~ms}$, respectively. The curves for the DMFC are labeled according to site, owing to their greater variability

train duration were fixed at $150 \mathrm{~Hz}$ and $400 \mathrm{~ms}$, respectively. For both the DMFC and FEF, the threshold declined for pulse durations between 0.05 and $0.3 \mathrm{~ms}$, and the threshold leveled off between 0.3 and $0.5 \mathrm{~ms}$. For all levels of pulse duration, the current threshold to evoke a saccade was always higher for the DMFC than FEF $[P$ $<0.002$ for all comparisons, using a Bonferroni correction for $P<0.01: 0.05 \mathrm{~ms}, t(4)=10.8 ; 0.1 \mathrm{~ms}, t(4)=10.6$; $0.2 \mathrm{~ms}, t(4)=8.4 ; 0.3 \mathrm{~ms}, t(4)=7.9 ; \quad 0.4 \mathrm{~ms}, t(4)=10.6$; $0.5 \mathrm{~ms}, t(4)=8.2]$.

The lowest charge per phase needed to evoke saccades from the five different sites tested in the DMFC ranged from 24.5 to $30 \mathrm{nC} /$ phase; the lowest charge per phase needed to evoke saccades from the six different sites tested in $\mathrm{FEF}$ was much lower, ranging from 2.4 to $13.75 \mathrm{nC} /$ phase. The lowest values occurred at pulse durations of $0.05 \mathrm{~ms}$ for the DMFC and at pulse durations of less than $0.3 \mathrm{~ms}$ for the FEF. The values were obtained from Fig. $6 \mathrm{~A}$ by computing the charge delivered (duration in milliseconds $\times$ current in microamps to yield charge in nanocoulombs) at every level of pulse duration to evoke a saccade. 

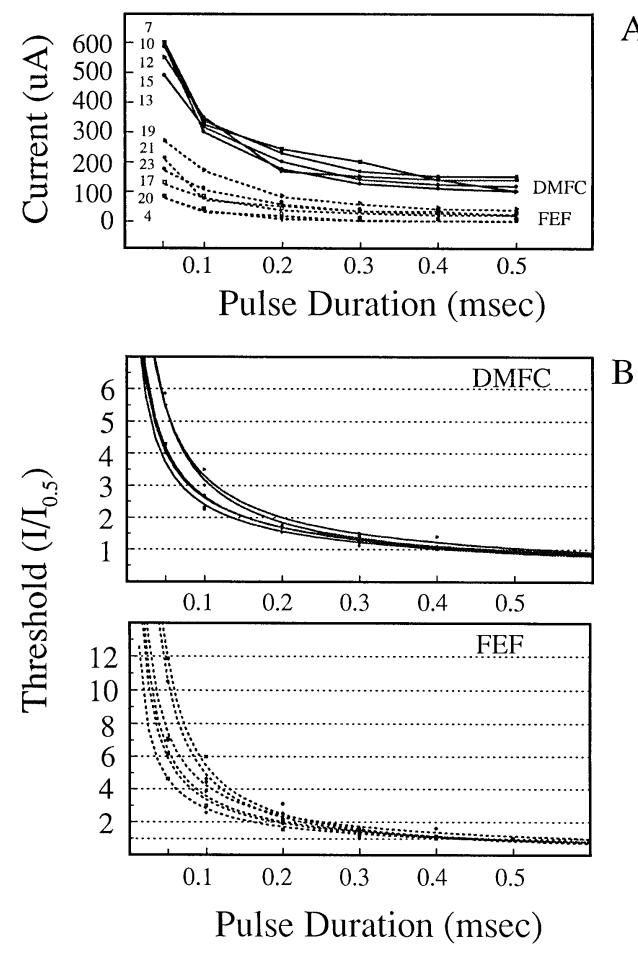

Fig. 6 A Current threshold plotted as a function of pulse duration for a $50 \%$ probability of evoking a saccade is shown for five sites in the DMFC (Fig. 1, penetration sites $7,10,12,13,15$ ) and six sites in the FEF (Fig. 1, penetration sites 4, 17, 19, 20, 21, 23). The pulse duration is the duration of one pulse of a symmetrical biphasic pair. The frequency used was $150 \mathrm{~Hz}$, and the train duration was fixed at $400 \mathrm{~ms}$. Each curve represents data from one stimulation site as indicated. B The curves from above are normalized and fitted to power functions (Tehovnik and Lee 1993). Current (I) is represented as the threshold current over the rheobase current $\left(I_{0.5}\right)$ plotted against pulse duration (milliseconds) for the DMFC and FEF (for each curve $R^{2}>0.94, N=6$ )

Data in Fig. 6A were normalized to the current threshold at the 0.5-ms duration, the rheobase current, and fitted to power functions (Tehovnik and Lee 1993). These curves were used to estimate the chronaxie, the pulse duration at twice the rheobase current (Fig. 6B). For the DMFC and FEF, the chronaxies were similar, ranging from 0.12 to $0.24 \mathrm{~ms}$, although on average the chronaxies were somewhat shorter for the DMFC (i.e., $0.16 \mathrm{~ms}$ ) than the FEF (i.e., $0.20 \mathrm{~ms}$ ). These differences were not significant, however $[t(4)=2.05, P>0.05]$.

\section{Discussion}

\section{Chronaxies and effective current spread}

The evocation of saccades required higher currents when stimulating the DMFC than when stimulating the FEF, yet the estimated chronaxies for these areas were similar, ranging from 0.12 to $0.24 \mathrm{~ms}$. This range overlapped with that reported previously for the DMFC, i.e., $0.1-0.2 \mathrm{~ms}$ (Tehovnik and Lee 1993). Moreover, this range over- lapped with the range of chronaxies for pyramidal tract neurons, i.e., 0.1-0.22 ms (Asanuma et al. 1976; Stoney et al. 1968). Even though higher currents were needed to evoke saccades from the DMFC than the FEF, their similar chronaxies suggest that the neural substrates mediating saccades within each region have similar excitability properties. ${ }^{1}$ This suggestion concurs with the observation that DMFC and FEF corticotectal cells, which are probably activated during electrical stimulation of DMFC and FEF, have similar diameters ranging from 10 to $45 \mu \mathrm{m}$ (Fries 1984, Fig. 16).

At a $0.2-\mathrm{ms}$ pulse duration, the amount of current, on average, required to evoke saccades from the DMFC was $203 \mu \mathrm{A}$, and the amount of current, on average, required to evoke saccades from the FEF was $49 \mu \mathrm{A}$ (Fig. 6A). A $203-\mu \mathrm{A}$ and $49-\mu \mathrm{A}$ current is estimated to activate low-threshold neurons within $0.86 \mathrm{~mm}$ and $0.42 \mathrm{~mm}$ from the electrode tip, respectively, using the formula effective current spread $=(\text { current } / K)^{1 / 2}($ Tehovnik 1996), where $K$ is $272 \mu \mathrm{A} / \mathrm{mm}^{2}$ for the most excitable pyramidal tract cells (Stoney et al. 1968). A 203- $\mu$ A and 49$\mu \mathrm{A}$ current is estimated to activate high-threshold neurons within $0.24 \mathrm{~mm}$ and $0.12 \mathrm{~mm}$ from the electrode tip, respectively, where $K$ is $3460 \mu \mathrm{A} / \mathrm{mm}^{2}$ for the least excitable pyramidal tract cells (Stoney et al. 1968).

\section{Volume of neurons activated}

The number of cells within a cylinder of constant crosssectional area of $1 \mathrm{~mm}^{2}$ of cortex is remarkably constant across different mammalian species and their different cortical areas (Bok 1959; Braitenberg and Schuz 1991; Rockel et al. 1980). Rockel et al. (1980) counted roughly 120000 neurons $/ \mathrm{mm}^{2}$ through the entire depth of the cerebral cortex of mammals (including monkeys), which can vary in thickness from 1 to $3 \mathrm{~mm}$ depending on the species and cortical area. The cortical thickness of the DMFC and FEF in monkeys is approximately $2.0 \mathrm{~mm}$ (Winters et al. 1969). Therefore, the number of neurons within these cortical areas is roughly 60 cells $/ 0.001 \mathrm{~mm}^{3}$.

The volume of neurons activated directly by a $203-\mu \mathrm{A}$ and $49-\mu \mathrm{A}$ current would be $2.66 \mathrm{~mm}^{3}\left[4 / 3 \pi(r)^{3}\right.$, where $r=0.86 \mathrm{~mm}]$ and $0.31 \mathrm{~mm}^{3}\left[4 / 3 \pi(r)^{3}\right.$, where $\left.r=0.42 \mathrm{~mm}\right]$ for the most excitable neurons $\left(K=272 \mu \mathrm{A} / \mathrm{mm}^{2}\right)$, for example. Thence, the total number of neurons activated directly in the DMFC to evoke saccades is estimated to be 8-9 times higher than the total number activated directly in the FEF, since the volume of neurons activated with a $203-\mu \mathrm{A}$ current in the DMFC is 8-9 times greater than the

\footnotetext{
${ }^{1}$ The more excitable an element the shorter the chronaxie, such that large, myelinated axons have shorter chronaxies than small, nonmyelinated axons. The chronaxie is presumed to be 0.7 times the time constant of an electrically stimulated membrane (Ranck 1975), which depends on a membrane's resistance and capacitance (Bostock 1983; Bostock et al. 1983). The chronaxie is negatively correlated with the conduction velocity of axons (West and Wolstencroft 1983) and positively correlated with the refractory period of axons (Schizgal et al. 1991).
} 
volume activated with a $49-\mu \mathrm{A}$ current $^{2}$ and since the packing density of neurons is comparable between the two regions. ${ }^{3}$

Why is it necessary to activate substantially more neurons in the DMFC than the FEF to evoke saccadic eye movements, even though the excitability of these neurons is comparable? One possibility is that the DMFC is more functionally heterogeneous. It has been suggested that neurons in DMFC mediate both eye and forelimb movements (Bon and Lucchetti 1992; Mann et al. 1988; Mushiake et al. 1996; Schall 1991a). Therefore, unlike the FEF, which has been associated exclusively with oculomotor behavior (Bizzi 1968; Bizzi and Schiller 1970; Bruce and Goldberg 1985; Bruce et al. 1985; Mushiake et al. 1996; Robinson and Fuchs 1969; Schall 1991b; Schiller 1977; Schiller et al. 1980) the DMFC seems to mediate oculomotor as well as skeletomotor behavior. If neurons mediating oculomotor and skeletomotor functions are intermixed within the DMFC, then higher current thresholds might be expected for saccade evocation, since only a fraction of the neurons subserve this behavior.

\section{Frequency}

When applying a range of pulse frequencies to the FEF, saccades were evoked readily using frequencies as low as $50 \mathrm{~Hz}$ and as high as $1000 \mathrm{~Hz}$ while holding charge per phase and train duration constant. When high-frequency pulses (i.e., more than $200 \mathrm{~Hz}$ ) were delivered to the DMFC, however, the probability of evoking saccades decreased with increases in frequency for many sites, which concurs with a previous report (Tehovnik and Lee 1993). The optimal frequency of pulses for eliciting saccades from the DMFC was about $150 \mathrm{~Hz}$, which has also been found optimal for inhibiting saccades once the eyes are located within a termination zone (Tehovnik and Lee 1993).

The foregoing might suggest that neurons mediating saccades in the FEF follow pulse frequencies up to $1000 \mathrm{~Hz}$, whereas such neurons in the DMFC do not follow such high frequencies reliably. Small, unmyelinated fibers conduct high-frequency action potentials poorly (Swadlow et al. 1980; Swadlow and Waxman 1978), but the estimated chronaxie values of the DMFC and FEF were similar and the values suggest that the axons of the neurons activated were myelinated and large (Asanuma et al. 1976; Stoney et al. 1968).

\footnotetext{
${ }^{2}$ A similar ratio results when making estimates for the least excitable neurons $\left(K=3460 \mu \mathrm{A} / \mathrm{mm}^{2}\right)$ or when making estimates for currents used with $0.1-\mathrm{ms}$ pulse durations (i.e., $326 \mu \mathrm{A}$ for DMFC and $88 \mu \mathrm{A}$ for FEF using adjusted $K$-values of 490 $\mu \mathrm{A} / \mathrm{mm}^{2}$ for low-threshold elements and $6228 \mu \mathrm{A} / \mathrm{mm}^{2}$ for high-threshold elements; see Tehovnik 1996).

${ }^{3}$ To our knowledge no one has done a quantitative study comparing the packing densities of neurons in the DMFC with those of the FEF within one monkey. For the purpose of our calculation we have assumed that the densities are comparable. The packing densities of DMFC and FEF corticopontine cells, which are probably activated during stimulation of the DMFC and FEF, appear similar within the same monkey (Leichnetz et al. 1984, their Fig. 3).
}

The peak following-frequency of myelinated fibers stimulated with a train of pulses varies as a function of the conduction velocity of axons (Paintal 1965): for axons exhibiting conduction velocities of $10-60 \mathrm{~m} / \mathrm{s}$, the peak following-frequency varied from 300 to $900 \mathrm{im}-$ pulses/s. When the peak following-frequency was surpassed, the frequency of evoked impulses dropped. It is possible that the peak following-frequency of neurons in the DMFC was surpassed in the present study; however, the conduction velocities of corticofugal neurons of the DMFC and FEF projecting through the midbrain or brainstem are comparable, ranging from 5 to $60 \mathrm{~m} / \mathrm{s}$ (Macpherson et al. 1982; Segraves 1992; Segraves and Goldberg 1987).

The poor responsivity of the DMFC to high frequencies might instead be related to the excitability of terminal branches (Goldstein 1978; Raymond and Lettvin 1978; Swadlow et al. 1980; Swadlow and Waxman 1978). This possibility could be tested. Let us suppose that the refractory period of the terminal branches of DMFC neurons mediating saccades is greater than the refractory period of the terminal branches of FEF neurons (indicating that DMFC terminals are less excitable than FEF terminals). The DMFC and FEF could be electrically stimulated with pulse pairs delivered in a train such that a test pulse follows a conditioning pulse by an adjustable interval to ascertain the frequency threshold to evoke saccades at different intervals. Such a method has been used to differentiate the refractory period distributions of different fibers mediating a variety of behaviors (Tehovnik and Yeomans 1986, 1987, 1988; Yeomans 1975, 1979, 1990, 1995; Yeomans and Tehovnik 1988) and could very well be used to assess the excitability of DMFC and FEF terminals.

That the FEF follows higher frequencies than the DMFC might suggest that the FEF is more involved in saccade initiation (which would require the precise timing of action potentials (Swadlow and Waxman 1978)) than is the DMFC. Recent work by Hanes et al. (1995) showed that the timing of the burst prior to saccade initiation was less variable and more time-locked to saccade initiation for FEF cells than for DMFC cells.

\section{Train duration}

The delivery of long pulse trains (i.e., $>200 \mathrm{~ms}$ ) was typically necessary for evoking saccades from the DMFC, whereas the delivery of short pulse trains (i.e., $<100 \mathrm{~ms}$ ) was sufficient for evoking saccades from the FEF. It should be noted that train duration was tested in the present study with the eyes initially in ipsilateral craniotopic space. This minimizes the train duration needed to evoke saccades from the DMFC. Longer train durations are required for evoking saccades from the DMFC when the initial eye position is close to the termination zone (which can be in contralateral or central craniotopic space; Tehovnik and Lee 1993). Such variability in required train duration has never been reported for the 
FEF (Bruce et al. 1985; Goldberg and Bruce 1990; Marrocco 1978; Robinson and Fuchs 1969; Schall 1991b; Schiller 1977; Tehovnik and Lee 1993).

Pulse trains of $100 \mathrm{~ms}$ or less were sufficient to evoke saccades from the FEF. This concurs with the finding that FEF neurons begin to burst $100 \mathrm{~ms}$ or less before saccade execution (Hanes et al. 1995). Pulse trains of over $200 \mathrm{~ms}$ were usually required to evoke saccades from the DMFC. This agrees with the finding that DMFC neurons begin to discharge as early as $400 \mathrm{~ms}$ before saccade execution (Hanes et al. 1995). Whether the onset-time of bursting for DMFC units is affected by starting eye position remains to be determined.

\section{Electrode-tip size}

When parameters of Russo and Bruce $(1993 ; 50-\mu \mathrm{A}$ current, $0.2-\mathrm{ms}$ pulse duration, $350-\mathrm{Hz}$ frequency, $70-\mathrm{ms}$ pulse train) were used in the DMFC, saccades were never evoked from any sites tested in this study. A known major difference between the two studies is in the impedance of the electrodes. The impedance of the electrodes of our study ranged from 0.1 to $0.2 \mathrm{M} \Omega(1 \mathrm{kHz})$; the impedance of the electrodes of Russo and Bruce ranged from 0.5 to $1.0 \mathrm{M} \Omega(1 \mathrm{kHz})$. From the impedance values, the estimated surface area of our electrode tips ${ }^{4}$ ranged from 0.003 to $0.008 \mathrm{~mm}^{2}$ and the estimated surface area of those of Russo and Bruce ranged from 0.0003 to $0.0008 \mathrm{~mm}^{2}$. Thus the surface area of our electrodes was estimated to be 10 times greater than that of Russo and Bruce.

This apparent difference in tip size might account for our inability to evoke saccades from the DMFC using $50-\mu \mathrm{A}$ currents, even though this was accomplished by Russo and Bruce (1993) using comparable behavioral conditions (i.e., monkeys in our study and theirs were rewarded for fixating a light spot during stimulation). Higher currents are needed to activate neurons through largetipped electrodes as compared to small-tipped electrodes (Bagshaw and Evans 1976; West and Wolstencroft 1983), and higher currents are needed to evoke behavioral response when large-tipped electrodes are used than when small-tipped electrodes are used (Milner and Laferriere 1985).

\section{Charge density and tissue damage}

Any electrical stimulation study has the potential to cause neuronal damage. Neuronal damage has been associated with charge density at the electrode tip (Agnew et al. 1983; Brown et al. 1977; Bullara et al. 1983; McCreery et al. 1990; Yuen et al. 1981). McCreery et al. (1990) found that a charge density greater than $16000 \mathrm{nC} / \mathrm{mm}^{2}$ per phase delivered through a $0.007-\mathrm{mm}^{2}$ electrode (which is a similar tip surface area to that used in our

\footnotetext{
${ }^{4}$ The surface area was determined using the formula, surface area $=0.0003 /$ impedance ${ }^{1.4}$, derived from Lemon $(1983$, p. 74$)$ for platinum-iridium electrodes.
}

study) produced histological damage at the electrode tip when stimulation was delivered for many hours. The current densities used in the present study were generally lower than $16000 \mathrm{nC} / \mathrm{mm}^{2}$ per phase. The charge per phase used in the present study was typically $40 \mathrm{nC}$ $[400 \mu \mathrm{A} \times 0.1 \mathrm{~ms}]$, and the charge density generated at the electrode tips was 5000 to $13333 \mathrm{nC} / \mathrm{mm}^{2}$ per phase [ $40 \mathrm{nC} / 0.008 \mathrm{~mm}^{2}$ per phase to $40 \mathrm{nC} / 0.003 \mathrm{~mm}^{2}$ per phase]. Although the charge per phase used by Russo and Bruce (1993) was lower [i.e., $10 \mathrm{nC}, 50 \mu \mathrm{A} \times 0.2 \mathrm{~ms}$ ] than that used in the present study, the charge density generated at their electrode tips was actually somewhat higher than that used in the present study, ranging from 12500 to $33000 \mathrm{nC} / \mathrm{mm}^{2}$ per phase $\left[10 \mathrm{nC} / 0.0008 \mathrm{~mm}^{2}\right.$ per phase to $10 \mathrm{nC} / 0.0003 \mathrm{~mm}^{2}$ per phase].

Cathodal pulses with charge densities as high as $438 \mathrm{nC} / \mathrm{mm}^{2}$ per phase are required to activate extremely unexcitable neurons $1 \mathrm{~mm}$ away from the electrode tip [the value was derived from Nowak and Bullier 1996: $27500 \mu \mathrm{A} / \mathrm{mm}^{2} \times 0.2 \mathrm{~ms}$ pulses $/ 4 \pi$ per phase]. The charge densities generated at the electrode tip in the current study exceeded this value. Therefore, elements in contact with our electrode tips were always being activated at suprathreshold levels.

The use of high charge densities at the electrode tip when using cathodal pulses has been found to transiently inhibit the excitability of individual fibers next to the electrode tip (Katz and Miledi 1965; Roberts and Smith 1973). Katz and Miledi (1965) have attributed this inhibition to hyperpolarization blockade of the surround. The charge densities used by these investigators exceeded $100000 \mathrm{nC} / \mathrm{mm}^{2}$ per phase, which is far in excess of the charge densities used in the current study (see Tehovnik 1996 for further details).

\section{The supplementary eye fields and DMFC}

We have argued that one reason why we could not evoke saccades from the DMFC using the parameters of Russo and Bruce (1993) is due to differences in electrode tip exposure. Although most unlikely, it is conceivable tht the stimulation sites investigated in this report did not include the supplementary eye fields as investigated by Russo and Bruce (1993). Their supplementary eye field seems to lie in the extreme rostral part of the DMFC (see Tehovnik 1995, Fig. 3A). Regardless of whether our sites include their supplementary eye field, it is clear from the current study that one cannot legitimately claim that electrical stimulation affects different brain areas identically if one has not determined the optimal parameters for eliciting saccades from each area.

Investigators have been unable to evoke saccades from caudal DMFC, contributing to the impression that caudal DMFC is not part of an eye field (e.g., Huerta and Kaas 1990; Mitz and Wise 1987; Parthasarathy et al. 1992; Russo and Bruce 1993; Schall 1991b; Schlag and Schlag-Rey 1987) even though neurons with oculomotor-related discharge are found there (Bon and Lucchetti 
1992; Lee and Tehovnik 1995; Mann et al. 1988; Schall 1991a). The present results suggest that their failure to evoke saccades from caudal DMFC is due, in part, to their use of suboptimal stimulation parameters (as well as due to fixations in central craniotopic space when termination zones are situated centrally; e.g., Fig. 2; Lee and Tehovnik 1995; Tehovnik and Lee 1993; Tehovnik et al. 1994). Optimal parameters for the DMFC are currents that are greater than $200 \mu \mathrm{A}$ (Fig. 3), train durations that are greater than or equal to $400 \mathrm{~ms}$ (Fig. 4), pulse frequencies that are approximately $150 \mathrm{~Hz}$ (Fig. 5), and pulse durations ranging from 0.1 to $0.2 \mathrm{~ms}$ (Fig. 6). These parameters are necessary for evoking saccades from the DMFC such that they terminate in one location of craniotopic space (e.g., Fig. 2; Lee and Tehovnik 1995; Tehovnik and Lee 1993; Tehovnik et al. 1994). Insufficient currents can fail to evoke saccades (Fig. 3) or cause the evoked saccades to be foreshortened, appearing to be of constant "vector" rather than being directed to a termination zone (Tehovnik and Lee 1993).

Optimal stimulation of DMFC is also important if one wants to examine the inhibition of saccades when the eyes are located in a termination zone. Tehovnik and Lee (1993) found that currents of $400 \mu \mathrm{A}(0.1-\mathrm{ms}$ pulse duration) were required to reliably fix a monkey's eyes to a termination zone and inhibit all visually evoked saccades, but a $100-\mu \mathrm{A}$ current was insufficient. Furthermore, the frequency required to fix the eyes in a termination zone ranged from 60 to $200 \mathrm{~Hz}$ (Tehovnik and Lee 1993), which concurs with the frequency range required to evoke saccades from eccentric locations to a termination zone (Fig. 5). With these optimal parameters, the eyes can be held in the termination zone with train durations as long as $1200 \mathrm{~ms}$ (Tehovnik and Lee 1993).

\section{Conclusion}

The present results contribute to the body of work demonstrating that the DMFC and FEF have different properties with respect to oculomotor behavior. The evocation of saccades via electrical stimulation from DMFC and FEF requires different ranges of current, frequency, and train duration, yet similar ranges of pulse duration. When studying a brain region that has newly recognized motor properties, such as it seems crucial to routinely perform parametric tests of electrical stimulation, in order to characterize the region and in order to deduce the parameters that optimize the evoked response (Tehovnik 1996; Tehovnik and Lee 1993).

Acknowledgements This work was supported by NIH EY08502 to P.H. Schiller. We would like to thank I-Han Chou and Peter Schiller for taking the time to review this work. Finally, we express many thanks to Warren Slocum for valuable discussions on the biophysics of brain stimulation.

\section{References}

Agnew WF, Yeun TGH, McCreery DB (1983) Morphologic changes after prolonged electrical stimulation of the cat's cortex at defined charge densities. Exp Neurol 79:397-411

Asanuma H, Arnold A, Zarzecki P (1976) Further study on the excitation of pyramidal tract cells by intracortical microstimulation. Exp Brain Res 26:443-461

Bagshaw EV, Evans MH (1976) Measurement of current spread from microelectrodes when stimulating within the nervous system. Exp Brain Res 25:391-400

Bizzi E (1968) Discharge of frontal eye field neurons during saccadic and following eye movements in unanesthetized monkeys. Exp Brain Res 6:69-80

Bizzi E, Schiller PH (1970) Single unit activity in the frontal eye fields of unanesthetized monkeys during head and eye movements. Exp Brain Res 10:151-158

Bok ST (1959) Histonomy of the cerebral cortex. Elsevier, Amsterdam

Bon L, Lucchetti C (1992) The dorsomedial frontal cortex of the macaca monkey: fixation and saccade-related activity. Exp Brain Res 89:571-580

Bostock H (1983) The strength-duration relationship for excitation of myelinated nerve: computed dependence on membrane properties. J Physiol (Lond) 341:59-74

Bostock H, Sears TA, Sherratt RM (1983) The spatial distribution of excitability and membrane current in normal and demyelinated mammalian nerve fibres. J Physiol (Lond) 341:41-58

Braitenberg V, Schuz A (1991) Anatomy of the cerebral cortex. Springer, Berlin Heidelberg New York

Brown WJ, Babb TL, Soper HV, Lieb JP, Ottino CA, Crandall PH (1977) Tissue reactions for long-term electrical stimulation of the cerebellum in monkeys. J Neurophysiol 47:366-379

Bruce CJ, Goldberg ME (1985) Primate frontal eye fields. I. Single neurons dirscharging during saccades. J Neurophysiol 53:603635

Bruce CJ, Goldberg ME, Bushnell MC, Stanton GB (1985) Primate frontal eye fields. II. Physiological and anatomical correlates of electrically evoked eye movements. J Neurophysiol 54:714-734

Bullara LA, McCreery DB, Yuen TGH, Agnew WF (1983) A microelectrode for delivery of defined charge densities. J Neurosci Methods 9:15-21

Fries W (1984) Cortical projections to the superior colliculus in the macaque monkey: a retrograde study using horseradish peroxidase. J Comp Neurol 230:55-76

Gallistel CR, Schizgal P, Yeomans JS (1981) A portrait of the substrate for self-stimulation. Physiol Rev 88:228-273

Goldberg ME, Bruce CJ (1990) Primate frontal eye fields. III. Maintenance of spatially accurate saccade signal. J Neurophysiol 64:489-508

Goldstein SS (1978) Models of conduction in nonuniform axons. In: Waxman SG (ed) Physiology and pathobiology of axons. Raven Press, New York, pp 227-236

Hanes DP, Thompson KG, Schall JD (1995) Relationship of presaccadic activity in frontal eye field and supplementary eye field to saccade initiation in macaque: poisson spike train analysis. Exp Brain Res 103:85-96

Huerta MF, Kaas JH (1990) Supplementary eye field as defined by intracortical microstimulation: connections in macaque. J Comp Neurol 293:299-330

Judge SJ, Richmond BJ, Chu FC (1980) Implantation of magnetic search coils for measurement of eye position: an improved method. Vision Res 20:535-538

Katz B, Miledi R (1965) Propagation of electric activity in motor nerve terminals. R Soc Proc Lond 161:453-482

Lee KM, Tehovnik EJ (1995) Topographic distribution of fixationrelated units in the dorsomedial frontal cortex of the rhesus monkey. Eur J Neurosci 7:1005-1011

Lemon R (1983) Methods for neuronal recording in conscious animals. In: Smith AD (ed) Methods in the neurosciences. (IBRO handbook series). Wiley \& Smith, New York, pp 74-75 
Leichnetz GR, Smith DJ, Spencer RF (1984) Cortical projections to the paramedian tegmental and basilar pons in the monkey. J Comp Neurol 228:388-408

Macpherson J, Wiesendanger M, Maragoz C, Miles TS (1982) Corticospinal neurons of the supplementary motor area of monkeys. Exp Brain Res 48:81-88

Mann SE, Thau R, Schiller PH (1988) Conditional task-related responses in monkey dorsomedial frontal cortex. Exp Brain Res 69:460-468

Marrocco RT (1978) Saccades induced by stimulation of the frontal eye fields: interaction with voluntary and reflexive eye movements. Brain Res 146:23-34

McCreery DB, Agnew WF, Yuen TGH, Bullara L (1990) Charge density and charge per phase as cofactors in neural injury induced by electrical stimulation. IEEE Trans Biomed Eng 37:996-1001

Milner PM, Laferriere A (1985) Effect of electrode size on brain stimulation. Exp Neurol 89:603-615

Mitz AR, Wise SP (1987) The somatotopic organization of the supplementary motor area: intracortical microstimulation mapping. J Neurosci 7:1010-1021

Mushiake H, Fujii N, Tanji J (1996) Visually guided saccade versus eye-hand reach: contrasting neuronal activity in the cortical supplementary and frontal eye fields. J Neurophysiol 75:21872191

Nowak LG, Bullier J (1996) Spread of stimulating current in the cortical grey matter of rat visual cortex studied on a new in vitro slice preparation. J Neurosci Methods 67:237-247

Paintal AS (1965) Effects of temperature on conduction in single vagal and saphenous myelinated nerve fibres of the cat. J Physiol (Lond) 180:20-49

Parthasarathy HB, Schall JD, Graybiel AM (1992) Distributed but convergent ordering of corticostriatal projections: analysis of the frontal eye field and the supplementary eye field in the macaque monkey. J Neurosci 12:4468-4488

Ranck JB (1975) Which elements are excited in electrical stimulation of mammalian central nervous system: a review. Brain Res 98:417-440

Raymond SA, Lettvin JY (1978) Aftereffects of activity in peripheral axons as a clue to nervous coding. In: Waxman SG (ed) Physiology and pathobiology of axons. Raven Press, New York, pp 203-225

Roberts W, Smith DO (1973) Analysis of threshold currents during microstimulation of fibres in the spinal cord. Acta Physiol Scand 89:384-394

Robinson DA, Fuchs AF (1969) Eye movements evoked by stimulation of frontal eye fields. J Neurophysiol 32:637-648

Rockel AJ, Hiorns RW, Powell TPS (1980) The basic uniformity in structure of the neocortex. Brain 103:221-244

Russo GS, Bruce CJ (1993) Effect of eye position within the orbit on electrically elicited saccadic eye movements: a comparison of the macaque monkey's frontal and supplementary eye fields. J Neurophysiol 69:800-818

Schall JD (1991a) Neural activity related to visually guided saccadic eye movements in the supplementary motor area of rhesus monkeys. J Neurophysiol 66:530-558

Schall JD (1991b) Neuronal activity related to visually-guided saccades in the frontal eye fields of rhesus monkeys: a comparison with supplementary eye fields. J Neurophysiol 66:559-579

Schiller PH (1977) The effect of superior colliculus ablation on saccades elicited by cortical stimulation. Brain Res 122:154-156

Schiller PH, True SD, Conway JL (1980) Deficits in eye movements following frontal eye field and superior colliculus ablations. J Neurophysiol 44:1175-1189

Schizgal P, Conover K, Schindler D (1991) Medial forebrain bundle units in the rat: dependence of refractory period estimates on pulse duration. Behav Brain Res 42:151-160

Schlag J, Schlag-Rey M (1987) Evidence for a supplementary eye field. J Neurophysiol 57:179-200
Segraves MA (1992) Activity of monkey frontal eye field neurons projecting to oculomotor regions of the pons. J Neurophysiol 68:1967-1985

Segraves MA, Goldberg ME (1987) Functional properties of corticotectal neurons in the monkey's frontal eye field. J Neurophysiol 58:1387-1419

Sommer MA (1995) The role of the frontal cortex in the generation of saccadic eye movements and fixations. Doctoral dissertation, Massachusetts Institute of Technology, Cambridge, Mass

Sommer MA, Tehovnik EJ (1997) Reversible inactivation of macaque frontal eye field. Exp Brain Res (in press)

Stoney SD, Thompson WD, Asanuma H (1968) Excitation of pyramidal tract cells by intracortical stimulation: effective extent of stimulating current. J Neurophysiol 31:659-669

Swadlow HA, Waxman SG (1978) Activity-dependent variations in the conduction properties of central axons. In: Waxman SG (ed) Physiology and pathobiology aof axons. Raven Press, New York, pp 191-202

Swadlow HA, Kocsis JD, Waxman SG (1980) Modulation of impulse conduction along the axonal tree. Annu Rev Biophys Bioeng 9:143-179

Tehovnik EJ (1995) The dorsomedial frontal cortex: eye and forelimb fields. Behav Brain Res 67:147-163

Tehovnik EJ (1996) Electrical stimulation of neural tissue to evoke behavioural responses. J Neurosci Methods 65:1-17

Tehovnik EJ, Lee KM (1993) The dorsomedial frontal cortex of the rhesus monkey. Topographic representation of saccades evoked by electrical stimulation. Exp Brain Res 96:430-442

Tehovnik EJ, Sommer MA (1996) Compensatory saccades made to remembered targets following orbital displacement by electrically stimulating the dorsomedial frontal cortex or frontal eye fields of primates. Brain Res 727:221-224

Tehovnik EJ, Yeomans JS (1986) Two converging brainstem pathways mediating circling behavior. Brain Res 385:329-342

Tehovnik EJ, Yeomans JS (1987) Circling elicited from the anteromedial cortex and medial pons: refractory periods and summation. Brain Res 407:240-252

Tehovnik EJ, Yeomans JS (1988) Contraversive circling elicited from the internal capsule and substantia nigra: evidence for a continuous axon bundle mediating circling. Brain Res 441:269-280

Tehovnik EJ, Lee KM, Schiller PH (1994) Stimulation-evoked saccades from the dorsomedial frontal cortex of the rhesus monkey following lesions of the frontal eye fields and superior colliculus. Exp Brain Res 98:179-190

West DC, Wolstencroft JH (1983) Strength-duration characteristics of myelinated and non-myelinated bulbospinal axons in the cat spinal cord. J Physiol (Lond) 337:37-50

White JM, Sparks DL, Stanford TR (1994) Saccades to remembered target locations: an analysis of systematic and variable errors. Vision Res 34:79-92

Winters WD, Kado RT, Adey WR (1969) A stereotaxic atlas for Macaca nemestrina. University of California Press, Los Angeles

Yeomans JS (1975) Quantitative measurements for neural poststimulation excitability with behavioural methods. Physiol Behav 15:593-602

Yeomans JS (1979) The absolute refractory periods of self-stimulation neurons. Physiol Behav 22:911-919

Yeomans JS (1990) Principles of brain stimulation. Oxford University Press, New York

Yeomans JS (1995) Electrically-evoked behaviours: axons and synapses mapped with collision tests. Behav Brain Res 67:121-132

Yeomans JS, Tehovnik EJ (1988) Turning responses evoked by stimulation of visuomotor pathways. Brain Res Rev 13:235-259

Yuen TGH, Agnew WF, Bullara LA, Jacques S, McCreery DB (1981) Histological evaluation of neural damage from electrical stimulation: considerations for the selection of parameters for clinical application. Neurosurgery 9:292-299 